\title{
Konservasi Air Dan Penanggulangan Sumber Daya Air Pada Asrama Taruna Politeknik Penerbangan Indonesia Curug
}

\author{
Hendro Widiarto', Taryana $^{2}$, Pribadi Asih ${ }^{3}$, Yayuk Suprihartini ${ }^{4}$ \\ 1,2,3,4,5,6 Politeknik Penerbangan Indonesia Curug \\ e-mail: ${ }^{1}$ hendro.widiarto@ppicurug.ac.id, ${ }^{2}$ taryana@ppicurug.ac.id, ${ }^{3}$ pribadi.asih@ppicurug.ac.id, \\ ${ }^{4}$ yayuk.suprihartini@ppicurug.ac.id
}

\begin{abstract}
Abstrak
Politeknik Penerbangan Indonesia Curug adalah sebuah sekolah vokasi yang melaksanakan program pendidikan dan pelatihan dalam menyediakan tenaga terampil untuk memenuhi sumber daya manusia penerbangan. Salah satu permasalahan penting yang dialami peseta diklat dalam mengikuti proses pembalajaran yang harus tinggal di asrama yaitu persoalan kekurangan pemenuhan kebutuhan air. Pada musim kemarau kesulitan sumber air, tetapi pada musim penghujan banjir dan air tidak terserap tanah. Tujuan kegiatan ini adalah: member wawasan kepada pihak pimpinan sekolah untuk membangun hunian yang ramah lingkungan, menyadarkan masyarakat bahwa air menjadi urusan/tanggung jawab setiap orang, perbaikan manajemen pengelolaan sumber daya air. Metode pelaksanaan kegiatan ini adalah dengan melakukan penyuluhan dan pelatihan pembuatan sumur resapan, saluran biopori dan tandon air. Hasil yang dicapai dari kegiatan ini adalah taruna penghuni asrama sadar dan memahami akan pentingnya pengelolaan sumber daya air, baik disaat musim kemarau maupun musim hujan dan mampu mempraktekkan cara pembuatan saluran drainase dan tandon air.
\end{abstract}

Kata Kunci : Asrama. Biofori. Tandon air.

Abstract

The Indonesian Aviation Polytechnic Curug is a vocational school that carries out education and training programs in providing skilled personnel to meet aviation human resources. One of the important problems experienced by training participants in following the learning process that must live in the dormitory is the problem of lack of fulfillment of water needs. In the dry season it is difficult to source water, but during the rainy season the floods and water are not absorbed by the soil. The objectives of this activity are: to provide insights to school leaders to build environmentally friendly shelters, to make people aware that water is everyone's business / responsibility, to improve management of water resources management. The method of implementing this activity is by conducting counseling and training on making absorption wells, biopore channels and water reservoirs. The results achieved from this activity are that dormitory cadets are aware of and understand the importance of water resource management, both during the dry season and the rainy season and are able to practice how to make drainage channels and water reservoirs

Keywords : Dormitory, Biofori, Water reservoir.

\section{Pendahuluan}

Ada masalah klasik di kota-kota dataran rendah yaitu krisis air bersih. Saat kemarau kekeringan, masuk musim penghujan kebanjiran, karena perilaku manusia yang mengexploitasi sumber daya alam dengan penggalian pasir dari tanah daratan yang akan merusak eko sistem yang semula sebagai lahan yang subur untuk pertanian berubah fungsi danau buatan yang ditinggal tanpa adanya pemanfaatan lahan galian dan penggundulan pohon untuk kebutuhan manusia tanpa adanya penanaman kembali. 
Kenyataannya, persoalan yang multi kompleks akibat urbanisasi menyebabkan lahan di kota besar hamper ditutupi oleh bangunan dan daerah kedap air, karena tertutup semen. Lahanlahan yang semula menjadi penampungan air, kini diuruk menjadi perumahan.Alhasil, air tidak terserap, tetapi meluber dan menggenangi permukiman penduduk.

Demikian halnya permasalahan di Politeknik Penerbangan Indonesia Curug, dengan lahan yang lumayan luas tersebut salah satunya dibangunnya asrama untuk tempat tinggal peserta diklat dengan penghuni sekitar 1.500 orang Taruna.

Dengan jumlah yang cukup besar tersebut sebagian besar tinggal di AsramaCurug I danAsrama Tower (Alpha dan Bravo).Yang jadi masalah terletak pada pemanfaatan air bersih untuk kegiatan MCK, saat musim kemarau sering terjadi kekeringan beberapa sumur sumber sumber air bersih. Berbalik jika musim penghujan beberapa lokasi akan terjadi genangan bahkan air hujan masuk kedalam ruangan, karena ketika hujan air tidak terserap, tetapi meluber dan menggenangi permukiman. Disamping itu kesadaran dan pengetahuan masyarakat terhadap lingkungan relative kurang peka, setiap menghadapi permasalahan mengenai lingkungan diselesaikan dengan mengambil jalan pintas tanpa memikirkan dampak yang terjadi untuk jangka panjang, contohnya ;permasalahan timbulnya banjir akibat musim hujan diselesaikan hanya dengan cara membersihkan selokan dari sampah dan pavingisasi saja.

Permasalahan pertama yang dialami penghuni asrama Curug I adalah persoalan terkait kekurangan kebutuhan air yang senantiasa dihadapi oleh penghuni asrama (Taruna), hal ini tidak bisa hanya menjadi tanggung jawab manajemen saja, namun penghuni asrama selaku salah satu pemanfaat sumber daya air, seharusnya senantiasa ikut membantu mengurangi banjir dan kelangkaan air pada musim kemarau.

\section{Metode}

Tahapan-tahapan pelaksanaan kegiatan pengabdiaan ini sebagai berikut:

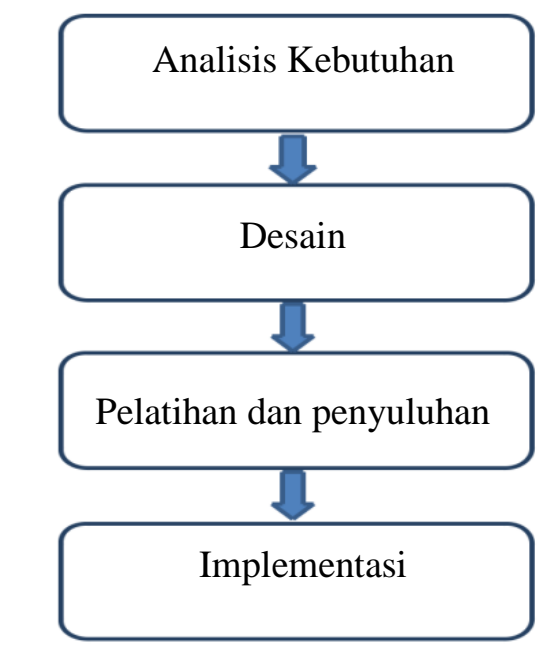

Gambar 1. Diagram alir Tahapan Kegiatan

Dari gambar1.dapat dijelaskan Tahapan kegiatan sebagai berikut:

A. Metode Analisis untuk Mengidentifikasi Lubang Resapan Biopori (LRB)

Dalam metoda ini dilakukan analisis kualitatif. Melalui analisis kualitatif ini dilakukan pengolahan data sekunder dan observasi lapangan mengenai Lubang Resapan Biopori (LRB) 
B. Metode Analisis Penentuan Lokasi yang Cocok di Terapkan Lubang Resapan Biopori (LRB)

Lubang Resapan Biopori (LRB) akan berfungsi dengan baik jika pembangunannya di suatu kawasan yang memenuhi persyaratan, yaitu : tanah harus mudah meloloskan air; dibangun tidak melebihi kedalaman permukaan air tanah (water table) dalam hal perancangan pembuatan biopori.

\section{Analisis Jenis Tanah}

Analisis jenis tanah ini juga dapat berguna untuk menentukan lokasi yang cocok, sehingga nantinya dapat dipergunakan dalam superimpose menurut jumlah skor dalam pembobotan. Permeabilitas adalah kemampuan tanah dalam diresapi air.

\section{Analisis Curah Hujan}

Analisis kualitatif ini dilakukan untuk menentukan lokasi yang cocok diterapkannya lubang resapan biopori.

\section{Analisis Kepadatan Bangunan}

Analisis yang dipakai untuk mengetahui kepadatan bangunan di wilayah penelitian adalah analisis KWT (Koefisien Wilayah Terbangun). KWT (Koefisien Wilayah Terbangun) adalah angka prosentase luas kawasan atau blok peruntukan yang terbangun terhadap luas kawasan atau luas blok peruntukan yang direncanakan

\section{Analisis Jumlah Kebutuhan Lubang Resapan Biopori (LRB)}

Analisis ini dilakukan setelah diketahui kawasan yang cocok diterapkannya bagi penempatan LRB

Untuk mengetahui kebutuhan Jumlah Lubang Resapan Biopori (LRB), perlu diketahui intensitas curah hujan terlebih dahulu, debit limpasan curah hujan, serta laju peresapan infiltrasi. Analisis ini dilakukan setelah diketahui kawasan yang cocok diterapkannya bagi penempatan LRB :

a. Analisis Intensitas Curah Hujan

Tujuan analisis ini adalah untuk mengetahui nilai intensitas hujan yang akan digunakan untuk perhitungan jumlah lubang resapan biopori di wilayah studi.

b. Analisis Debit limpasan air hujan

Air Limpasan/larian (run off) adalah bagian dari curah hujan yang mengalir di atas permukaan tanah menuju ke sungai, danau, dan lautan. Air hujan yang tidak sempat masuk ke dalam tanah dan oleh karenanya mengalir di atas permukaan tanah ke tempat yang lebih rendah

\section{Tahapan Pelaksanaan :}

a. Tahapan awal ini berupa analisis kebutuhan meliputi kebutuhan output, proses dan hasil analisa kebutuhan, dipresentasikan kepada kelompok masyarakat, untuk mendapatkan masukan yang sesuai dengan kebutuhan.

b. Tim membuat solusi alternatif yang sesuai dengan kebutuhan dan sumberdaya yang tersedia, agar solusi yang ditawarkan dapat dijalankan oleh pihak masyarakat dan pemerintahan desa dan tim menyepakati solusi yang dipilih untuk diterapkan.

\section{Penyuluhan dan pelatihan :}

\section{Penyuluhan :}

Dari hasil verifikasi dengan penghuni barak maka diputuskan Ayo rame-ramenabung air mandiri dengan metode : Lubang Serapan Biopori yang tindak lanjutnya dengan mengumpulkan penghuni barak (Asrama) untuk mengadakan pelatihan pembuatan Lubang serapan Biopori dan penyuluhan penanggulangan banjir pada musim hujan 
(Lubang Resapan Biopori menurut Peraturan Menteri Kehutanan Nomor: P.70/ Menhut-II/ 2008/ Tentang Pedoman Teknis Rehabilitasi Hutan dan Lahan, adalah lubanglubang di dalam tanah yang terbentuk akibat berbagai aktivitas organisme di dalamnya, seperti cacing, perakaran tanaman, rayap, dan fauna tanah lainnya)

Penyuluhan konservasi air hujan serta penerapan teknologi biopori pada asrama (Barak Curug 1) di atas berisi materi yang terkait dengan siklus hidrologi, ide dan saran pembuatan dan penerapan sumur resapan/biopori di sekitar tempat tinggal, pembuatan lubang untuk menapung air permukaan

\section{Pelatihan}

Tehnologi Biopori adalah suatu cara mempeluas bidang infiltrasi air dengan :

a. membuat lubang pada lahan dengan kedalaman sekitar 1 meter dan diameter $10 \mathrm{~cm}$ dengan alat bor sederhana.

b. Lubang tanah selanjutnya diperkuat dengan pralon PVC diameter $10 \mathrm{~cm}$ yang sudah dilubangi beberapa dan diberi tutup yang juga telah dilubangi (Gambar 3).

c. Lubang biopori dengan tutup tidak dilem, artinya dapat dibuka dan ditutup juga dapat digunakan sebagai tempat pembuangan sampah organik dapur, sehingga beberapa minggu kemudian dapat dipanen sebagai kompos untuk digunakan sebagai pupuk tanaman sayur mayurnya.

d. Secara keseluruhan penerapan teknologi biopori dapat dipakai sebagai sarana konservasi air, pengkomposan sampah organik keluarga dan pembrantasan sarang nyamuk.

e. Konservasi air harus dilakukan oleh setiap orang, setiap kelompok orang dari lembaga terkecil setingkat RT

\section{Implementasi}

Produk yang telah dibuat diimplementasikan ke Asrama Curug I dengan terlebih dahulu memberikan pelatihan / Penyuluhan Lubang serapan Biopori.

\section{Hasil dan Pembahasan}

\section{A. Hasil}

Hasil pelaksanaan Pengabdian Kepada Masyarakat (PPM) tentang Konservasi Sumber Daya Air/Menabung Air Saat Musim Kemarau Dan Penanggulangan Masalah Banjir Saat Musim Hujan Di Asrama Curug I adalah sebagai berikut:

\section{Kondisi Awal}

Penghuni Asrama Curug I kurang memahami tentang pentingnya hunian berwawasan lingkungan terkait pemanfaatan sumberdaya air. Mereka masih kurang pengetahuan/memahami cara pengelolaan sumberdaya air yang ada.

\section{Kondisi Akhir}

Setelah pelaksanaan program penyuluhan/pelatihan pemanfaatan sumberdaya air, penghuni Asrama Curug I mulai sadar akan pentingnya pengelolaan sumberdaya air yang ada dan ada upaya menerapkan sumur resapan serta tandon air

\section{B. Pembahasan}

Kegiatan Pengabdian Kepada Masyarakat dengan pembuatan Lubng Resapan Biopori di Asrama Curug I dengan melibatkan penghuni (Taruna). Diharapkan pelaksanaan ini yang mengikut sertakan kaum milenial adalah untuk menanamkan rasa cinta lingkungan khususnya pemanfaatan air, yang mana pada musim hujan air berlimpaah hingga terbuang percuma bahkan akan menimbulkan banjir di sekitar kita. 
Dengan menanamkan pemikiran tersebut harapan akan terbentuk pemuda yang mempunyai karakter cinta lingkungan dengan menerapkan konsep pembangunan berwawasan lingkungan yang berkelanjutan.

\section{Langkah-langkah membuat lubang biopori:}

- Tentukan lokasi yang akan dijadikan tempat pembuatan biopori, yaitu dihalam depan setiap barak dari Alpha s/d barak Hotel. Setiap barak jumlahnya 24 lubang . Pastikan lahan yang di pilih tidak dilapisi semen.

- Siram tanah yang akan dijadikan tempat pembuatan biopori dengan air agar tanah menjadi lebih lunak dan mudah dilubangi.

- Buat lubang di tanah dengan menggunakan bor tanah atau linggis. Jika tekstur tanah masih padat, siram lagi dengan air selama proses pengeboran hingga tanah menjadi lunak.

- Buatlah lubang dengan kedalaman sekitar 1 meter dengan menggunakan bor tanah diameter 5 “

- Setelah lubang yang diinginkan terbentuk, lapisi lubang menggunakan pipa PVC yang ukurannya sama dengan diameter lubang yaitu 5“

- Tutup lubang dengan tutup pipa PVC diameter 5 " yang sudah berlubang.

- Selesai

\section{Perawatan Biopori :}

1. Perhatikan kondisi sampah dalam lubang biopori kurang lebih 5 hari sekali

2. Angkat sampah dalam lubang biopori minimal 3 (tiga) bulan sekali untuk diangkat dan dijadikan pupuk kompos

3. Kemudian masukkan sampah organic bar uke dalam lubang biopori yang sudah kosong

Pada pembahasan kegiatan Pengabdian Kepada Masyarakat ini lingkup pekerjaannya yang diperlukan adalah :

\section{a. Alat dan bahan yang diperlukan:}

- Bor tanah

- Pipa PVC diameter 5 " panjangnya 1 meter yang bagian sisinya sudah dilubangi

- Penutup pipa pvc yang berlubang

- Air

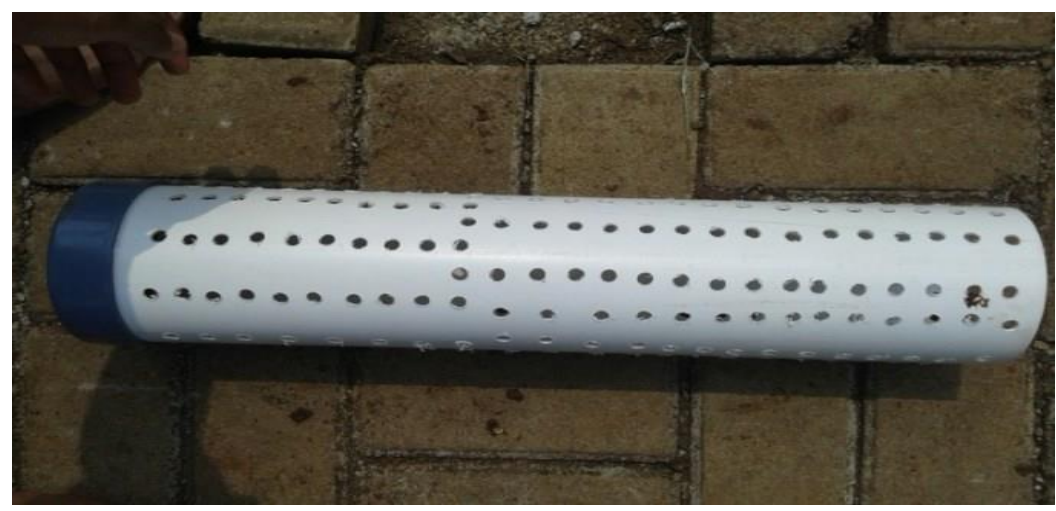

Pipa PVC diameter 5 “ panjangnya 1 meter yang sudah dilubangin 


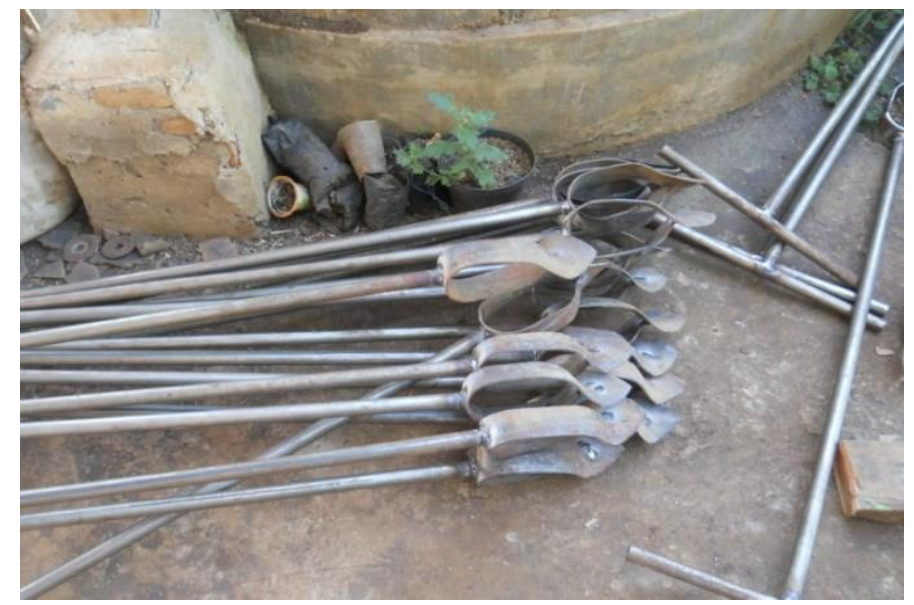

Bor tanah

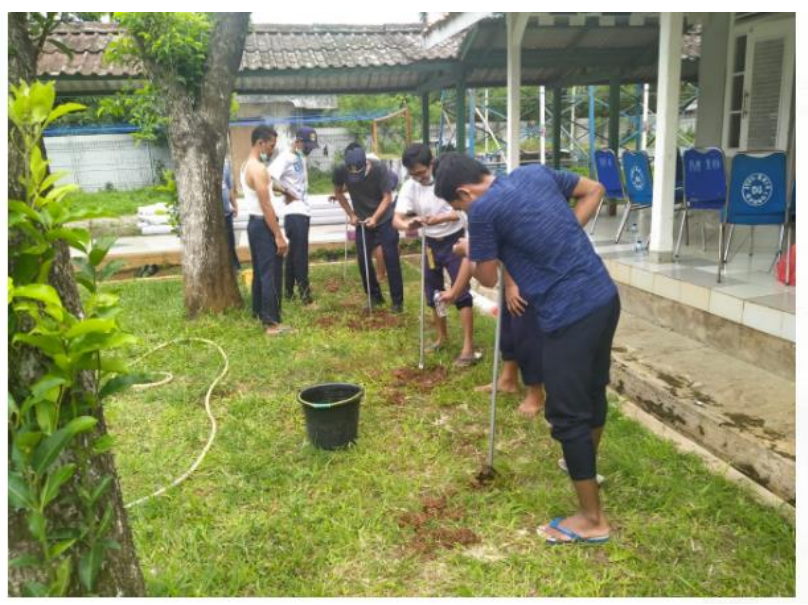

Pelaksanaan pembuatan biopori

Untuk mempermudah pembuatan lubang resapan biopori, ikuti tips dan trik berikut ini.

- Setiap mata bor masuk seluruhnya ke dalam tanah, tarik mata bor sambil diputar ke kanan, lalu bersihkan tanah yang terbawa mata bor. Setelah itu, lanjutkan kembali pengeboran tanahnya.

- Kita bisa melakukan penyiraman dengan air selama proses pengeboran agar lebih mudah melubangi tanah.

- Ketika terdapat bebatuan atau kerikil yang menghalangi, kita dapat menghentikan pembuatan lubang atau bisa dihilangkan terlebih dahulu batu yang mengganggu tersebut.

- Kalau tidak punya bor tanah, bisa juga digunakan linggis untuk membuat lubang

\section{Kesimpulan}

Kegiatan Pengabdian Kepada Masyarakat dalam bentuk pembuatan lubang biopori dengan pipa PVC 5 inch yang dipasang di barak Alfha sampai dengan Hotel dimaksudkan agar memeberikan wawasan kepada masyarakat atau penghuni asrama dan petugas kebersihannya tentang ramah lingkungan pemanfaatan tampung air hujan, dan hal ini juga menjadi tanggung jawab kita semua tentang perlu nyaman majemen pengelolaan sumber daya air untuk kebutuhan seharihari.. 


\section{Penghargaan/Ucapan terima kasih}

Dengan terlaksananya pengabdian kepada masyarakat tak terlepas akan bantuan moril serta materiil dan penulis menyadari bahwa dalam penulisan laporan ini atas dukungan semua pihak. Dan pada kesempatan ini penulis menyampaikan rasa terima kasih kepada Direktur Politeknik Penerbangan Indonesia Curug. Taruna penghuni Barak Alpha s/d Hotel Curug I dengan penuh antusias menyelesaikan kegiatan ini. Unit-unit terkait sehingga pelaksanaan kegiatan tanpa ada halangan. Terakhir diucapkan kepada tim kecil PKM Prodi yang memberikan bantuan pemikiran serta tenaga. Kepada semua pihak yang tidak dapat disebutkan satu persatu, penulis mengucapkan banyak terima kasih. Semoga bantuan dan dukungan yang diberikan kepada penulis bernilai amal ibadah disisi Allah Subhanahu Wata'ala. Amien

\section{Daftar Pustaka}

Bisri, Muhamad, 2008, “Teknologi Konservasi Sumber Daya Air”Materi Pelatihan Tenaga Ahli Konstruksi SDA - Departemen Pekerjaan Umum, 2008

Direktorat Jendral Sumber Daya Air Departemen Pekerjaan Umum, 2006, "Pengelolaan Banjir", Jakarta

Peraturan Pemerintah Nomor 121 tahun 2015 tentang Sumber Daya Air

Subyandono, Bambang, 2008, “Pengelolaan Sumbe rDaya Air Terpadu”, Materi Pelatihan Tenaga Ahli Konstruksi Sumber Daya Air, Departemen Pekerjaan Umum, Jakarta

Undang-Undang Nomor 32 Tahun 2009 mengenai Perlindungan dan Pengelolaan Lingkungan Hidup 